Supporting information

\title{
Automatic identification of lansoprazole degradants under stress conditions by LC-HRMS with MassChemSite and WebChembase
}

Stefano Bonciarelli, \pm Jenny Desantis, $\pm \S *$ Laura Goracci, \pm Lydia Siragusa, + Ismael Zamora $\dagger$ and Elisabeth Ortega-Carrasco ${ }^{* *}$

\pm Department of Chemistry, Biology and Biotechnology, University of Perugia, Via Elce di Sotto 8, 06123 Perugia

† Molecular Horizon SRL, Via Montelino 30, 06084 Bettona, Italy

† Lead Molecular Design, SL, Rambla del Celler 113 local, 08173 Sant Cugat del Vallès, Spain

Present Address $\S$ Department of Molecular Medicine, University of Padua, Via A. Gabelli 63, 35121 Padua, Italy 
Table S1. MassChemSite settings employed during this study. The differences between Agilent and Thermo instrument settings are annotated.

\begin{tabular}{|c|c|c|}
\hline Setting type & Setting name & Value \\
\hline \multirow[t]{9}{*}{ General } & Mass Spectrometer & $\begin{array}{l}\text { Agilent Q-TOF | Thermo } \\
\text { Orbitrap }\end{array}$ \\
\hline & Acquisition mode & Auto MS/MS | DDS \\
\hline & MSFile Converter & $\begin{array}{l}\text { MSFile-converter-2.3.9- } \\
\text { universal-msvc64 (only needed } \\
\text { for Thermo instrument) }\end{array}$ \\
\hline & Use retention time range (min) & None \\
\hline & Internal Standard & None \\
\hline & AutoSelect structures & True \\
\hline & Discard Structures with score below & 0 \\
\hline & Exclude products without formula & False \\
\hline & $\begin{array}{l}\text { Exclude products having an absolute } \\
\mathrm{m} / \mathrm{z} \text { diff }(\mathrm{ppm}=\text { above }\end{array}$ & False \\
\hline \multirow[t]{6}{*}{ Analog Signals } & Use UV peak area. Threshold (\%) & 0.20 (False for Thermo settings) \\
\hline & Use preset UV wavelength (nm) & True, 230 \\
\hline & Wavelength selection method & Area ratio \\
\hline & Retention time delay (min) & Automatic \\
\hline & Radiolabeled & False \\
\hline & Fluorescence & False \\
\hline \multirow{7}{*}{$\begin{array}{l}\text { Products } \\
\text { Generation }\end{array}$} & Minimum mass & 50 \\
\hline & Ignore products stereochemistry & True \\
\hline & Ignore redundant products & True \\
\hline & MIM (\%) & 30 \\
\hline & Reactions & See Table S1 \\
\hline & Number of product generations & 3 \\
\hline & Use constrained depiction & False \\
\hline \multirow[t]{6}{*}{ Peak detection } & Use maximum product count. Limit: & False \\
\hline & Area threshold & $0.50(\%) 0$ (absolute) \\
\hline & Peak detection smoothing & MEDIUM \\
\hline & Split computed peaks & False \\
\hline & Rescue computed peaks & False \\
\hline & Isotopes & Skip \\
\hline
\end{tabular}




\begin{tabular}{|c|c|c|}
\hline & Adducts & None \\
\hline & Neutral Losses & False \\
\hline & Multiple-Charge Ions & True, $\max \mathrm{z}=2$ \\
\hline & Dimeric Ions & False \\
\hline & Unexpected Products & True \\
\hline & Sum Areas & False \\
\hline Product Id & Reactant bond breaking limit & 4 \\
\hline & Break products limit & 3 \\
\hline & $\begin{array}{l}\text { Exclude fragments having an absolute } \\
\text { m/z diff (ppm) above: }\end{array}$ & False \\
\hline & $\begin{array}{l}\text { Break 6-membered heteroaromatic } \\
\text { rings }\end{array}$ & True \\
\hline & Oxidation during MS/MS & False \\
\hline & Bond breaking organizations & True all \\
\hline & $\begin{array}{l}\text { Bond breaking experimental } \\
\text { reorganizations }\end{array}$ & $\begin{array}{l}\text { Benzyl Alcohol and Aryl } \\
\text { Methoxy True; Amide Water } \\
\text { Loss and Allyl Sulphate False }\end{array}$ \\
\hline MS Options & Same peak tolerance (amu) & 0.010 \\
\hline & $\begin{array}{l}\text { Chromatogram automatic filtering } \\
\text { threshold }\end{array}$ & 0.97 \\
\hline & MS automatic filtering threshold & 0.95 \\
\hline & MS/MS automatic filtering threshold & 0.95 \\
\hline & Ionization Mode & Positive \\
\hline & Spectra comparisons & 2 \\
\hline & Signal Filtering & Automatic \\
\hline & Scan Filtering & Automatic \\
\hline
\end{tabular}


Table S2. Reactions defined in MassChemSite to be used in this study. The " $R$ " label refers to the nomenclature given by the software to define the pattern to find in the compound structure.

\begin{tabular}{|c|c|}
\hline Ether hydrolysis & $\begin{array}{l}\mathrm{R}_{1}-\mathrm{O}_{{ }_{\mathrm{R}}} \longrightarrow \mathrm{R}_{1}-\mathrm{OH}+\mathrm{R}_{2}-{ }^{-\mathrm{H}} \\
\mathrm{R}_{1}=\text { Carbon, } \mathrm{R}_{2}=\text { Carbon }\end{array}$ \\
\hline Ether oxidation (I) & $\begin{array}{l}\mathrm{R}_{1} \mathrm{O}_{\mathrm{R}_{2}} \longrightarrow \mathrm{R}_{1 \wedge \mathrm{O}} \mathrm{I}_{\mathrm{R}_{2}} \\
\mathrm{R}_{1}=\text { Carbon, } \mathrm{R}_{2}=\text { Carbon }\end{array}$ \\
\hline Ether oxidation (I) 2nd step & 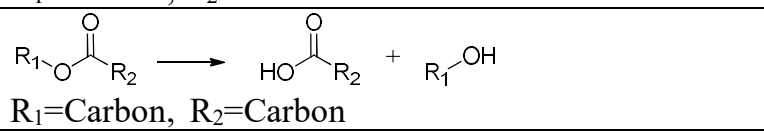 \\
\hline Ether oxidation (II) & $\begin{array}{l}\mathrm{R}_{1} \bigcirc \widehat{\mathrm{R}}_{2} \longrightarrow \mathrm{R}_{1} \mathrm{O} \hat{\mathrm{R}}_{\mathrm{R}_{2}}^{\mathrm{OH}} \\
\mathrm{R}_{1}=\text { Carbon, } \mathrm{R}_{2}=\text { Carbon }\end{array}$ \\
\hline Ether oxidation (II) 2nd step & 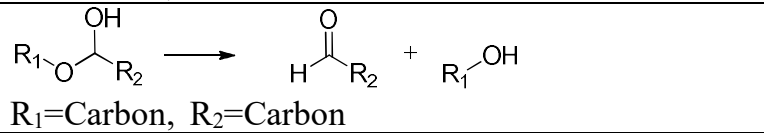 \\
\hline N-oxide formation & 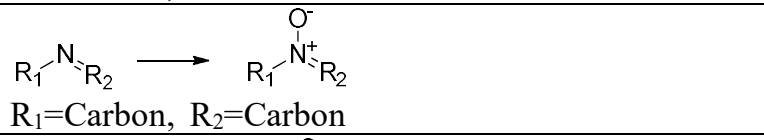 \\
\hline $\begin{array}{l}\text { Oxidative degradation } \\
\text { imidazole }\end{array}$ & 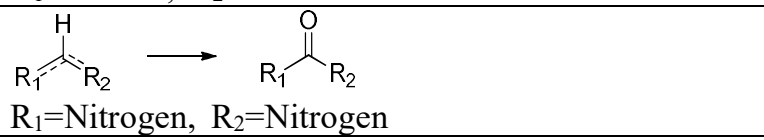 \\
\hline $\begin{array}{l}\text { Photo-degradation } \\
\text { benzimidazole }\end{array}$ & $\mathrm{R}_{\mathrm{R}_{1}=\text { Any atom }}^{\mathrm{H}}$ \\
\hline Photodegradation-S & 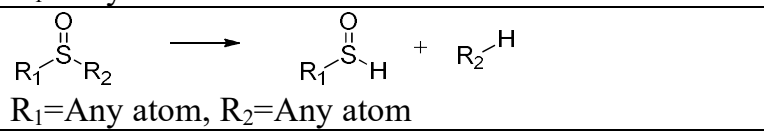 \\
\hline Sulphonamide acidification & $\begin{array}{l}\mathrm{O}_{i}^{\mathrm{O}} \\
\mathrm{R}_{1} \mathrm{~S}_{\mathrm{R}_{2}} \\
\mathrm{R}_{1}=\text { Carbon, } \mathrm{R}_{2}=\text { Nitrogen }\end{array}$ \\
\hline $\begin{array}{l}\text { Sulphoxide oxidation to } \\
\text { sulphone }\end{array}$ & 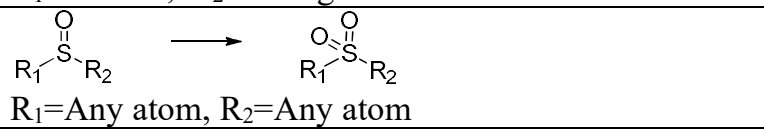 \\
\hline $\begin{array}{l}\text { Sulphoxide reduction to } \\
\text { alcohol }\end{array}$ & $\begin{array}{l}\mathrm{R}_{1}^{\mathrm{O}} \\
\mathrm{R}_{1}^{-\mathrm{S}_{\mathrm{R}_{2}}} \\
\mathrm{R}_{1}=\text { Any atom, } \mathrm{R}_{2}=\text { Any atom } \\
\mathrm{R}_{1}-\mathrm{SH}_{\mathrm{R}_{2}}\end{array}$ \\
\hline $\begin{array}{l}\text { Sulphoxide reduction to } \\
\text { sulphide }\end{array}$ & 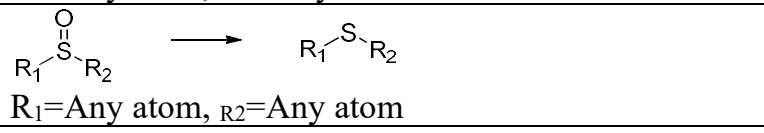 \\
\hline Thyol oxidation (I) & 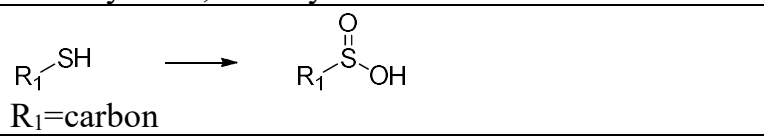 \\
\hline Thyol oxidation (II) & 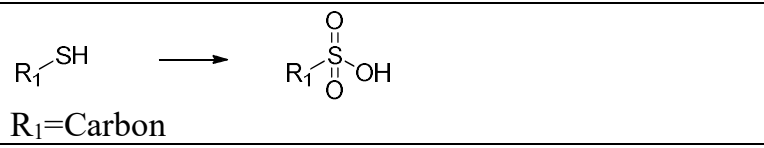 \\
\hline Thyol hydrolysis & $\begin{array}{l}\mathrm{R}_{1}=\mathrm{SH} \longrightarrow \mathrm{R}_{1}-\mathrm{OH} \\
\mathrm{R}_{1}=\text { Any atom }\end{array}$ \\
\hline Hydroxylation & $\begin{array}{l}\mathrm{R}_{1}^{-} \mathrm{H}^{\mathrm{H}} \longrightarrow \mathrm{R}_{1}^{-}{ }^{-\mathrm{OH}} \\
\mathrm{R}_{1}=\text { Carbon }\end{array}$ \\
\hline N-C-bonding & $\begin{array}{l}\mathrm{R}_{1}-\mathrm{N}^{\mathrm{R}_{2}+\mathrm{HN}^{\prime \prime}}=\mathrm{R}_{\mathrm{R}_{3}} \\
\mathrm{R}_{1}=\text { Carbon, } \mathrm{R}_{2}=\text { Carbon, } \mathrm{R}_{3}=\text { Any atom, } \mathrm{R}_{4}=\text { Any atom }\end{array}$ \\
\hline
\end{tabular}




\begin{tabular}{|c|c|}
\hline SO elimination & $\begin{array}{l}\mathrm{R}_{1}=\text { Any atom, } \mathrm{R}_{2}=\text { Any atom, } \mathrm{R}_{3}=\text { Any atom, } \mathrm{R}_{4}=\text { Any atom } \\
\mathrm{O}_{1}^{\prime \prime}-\mathrm{R}_{2}-\mathrm{R}_{2}-\mathrm{N}\end{array}$ \\
\hline Sulphur reorganization & 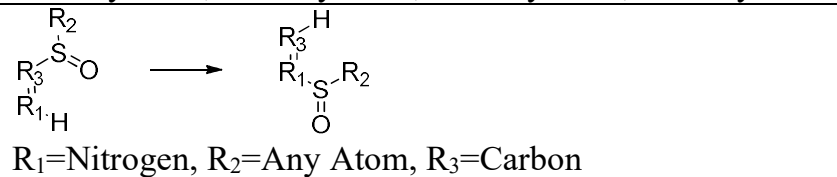 \\
\hline
\end{tabular}


Table S3. Summary of degradants found under acidic stress conditions obtained with the Q-Exactive instrument

\begin{tabular}{|l|l|l|l|l|}
\hline \multicolumn{1}{|c|}{ Name } & RT (min) & \multicolumn{1}{|c|}{$\mathbf{m} / \mathbf{z}$} & $\mathbf{m} / \mathbf{z ~ d i f f ~ ( p p m ) ~}$ & MS Area (\%) \\
\hline lansoprazole & $7.09-7.11$ & $370.0826-370.0837$ & $-1.40-1.64$ & $57.78-1.74$ \\
\hline DP-1 & $9.37-9.39$ & $354.0879-354.0898$ & $-4.39-0.99$ & $4.79-77.55$ \\
\hline DP-2 & $4.82-4.86$ & $322.1160-322.1172$ & $-0.62-3.10$ & $3.50-15.40$ \\
\hline DP-3 & 3.79 & $352.0724-352.0737$ & $-3.21-0.59$ & $0.72-3.02$ \\
\hline
\end{tabular}


Table S4. Summary of degradants found under oxidative stress conditions. Data obtained with Q-Exactive instrument

\begin{tabular}{|l|c|c|c|c|}
\hline \multicolumn{1}{|c|}{ Name } & RT (min) & $\mathbf{m} / \mathbf{z}$ & $\mathbf{m} / \mathbf{z ~ d i f f ~ ( p p m ) ~}$ & MS Area (\%) \\
\hline lansoprazole & 7.15 & $370.0826-370.0836$ & $-1.23-1.40$ & $100.0-92.20$ \\
\hline DP-4 & $7.49-7.50$ & $386.0775-386.0784$ & $-0.83-1.51$ & $0.60-4.13$ \\
\hline
\end{tabular}


Table S5. Summary of degradants found under basic stress conditions. Data obtained with Q-Exactive instrument

\begin{tabular}{|l|l|l|l|l|}
\hline \multicolumn{1}{|c|}{ Name } & RT (min) & $\mathbf{m} / \mathbf{z}$ & $\mathbf{m} / \mathbf{z ~ d i f f ~ ( p p m ) ~}$ & MS Area (\%) \\
\hline lansoprazole & $7.14-7.16$ & $370.0826-370.0837$ & $-1.40-1.42$ & $97.98-20.23$ \\
\hline DP-1 & $9.36-9.39$ & $354.0876-354.0888$ & $-1.43-1.88$ & $2.02-60.95$ \\
\hline DP-2 & $4.92-4.95$ & $322.1160-322.1165$ & $-0.62-0.93$ & $1.30-14.88$ \\
\hline DP-3 & $3.76-3.77$ & $352.0720-352.0730$ & $-1.29-1.76$ & $0.56-2.86$ \\
\hline DP-4 & $7.47-7.49$ & $386.0776-386.0786$ & $-1.44-1.23$ & $1.01-2.86$ \\
\hline
\end{tabular}


Table S6. Summary of degradants found under neutral stress conditions. Data obtained with Q-Exactive instrument

\begin{tabular}{|l|l|l|l|l|}
\hline \multicolumn{1}{|c|}{ Name } & RT (min) & $\mathbf{m} / \mathbf{z}$ & $\mathbf{m} / \mathbf{z ~ d i f f ~ ( p p m ) ~}$ & MS Area (\%) \\
\hline lansoprazole & $7.07-7.16$ & $370.0826-370.0839$ & $-1.99-1.51$ & $99.53-0.56$ \\
\hline DP-1 & $9.36-9.38$ & $354.0876-354.0888$ & $-1.51-1.68$ & $2.19-62.68$ \\
\hline DP-2 & $4.89-4.91$ & $322.1157-322.1167$ & $-1.55-1.56$ & $1.20-28.94$ \\
\hline DP-3 & $3.77-3.78$ & $352.0722-352.0730$ & $-1.04-1.10$ & $0.57-3.46$ \\
\hline DP-6 & $3.42-3.45$ & $272.0848-272.0855$ & $-0.92-1.46$ & $0.57-3.46$ \\
\hline
\end{tabular}




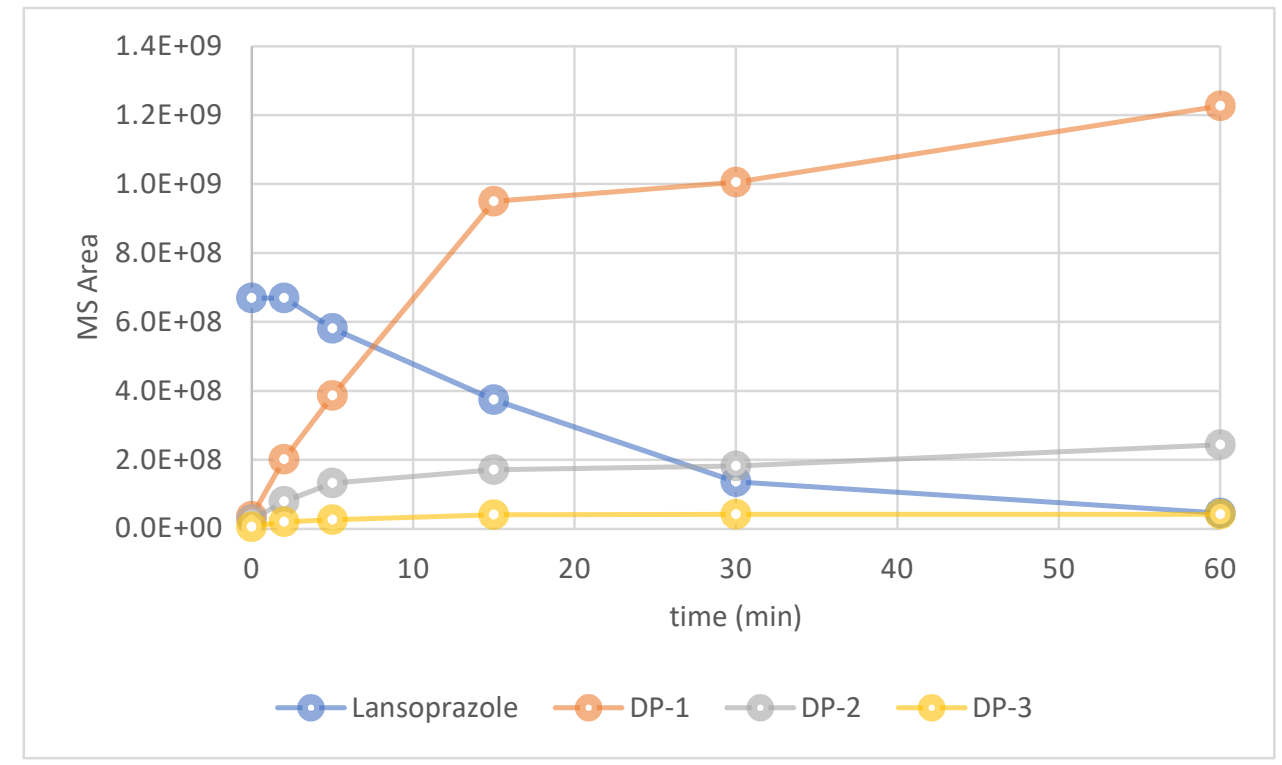

Figure S1. Time evolution of MS Area of lansoprazole and its found degradants under acidic conditions. Data obtained with Thermo Q-Exactive instrument. 

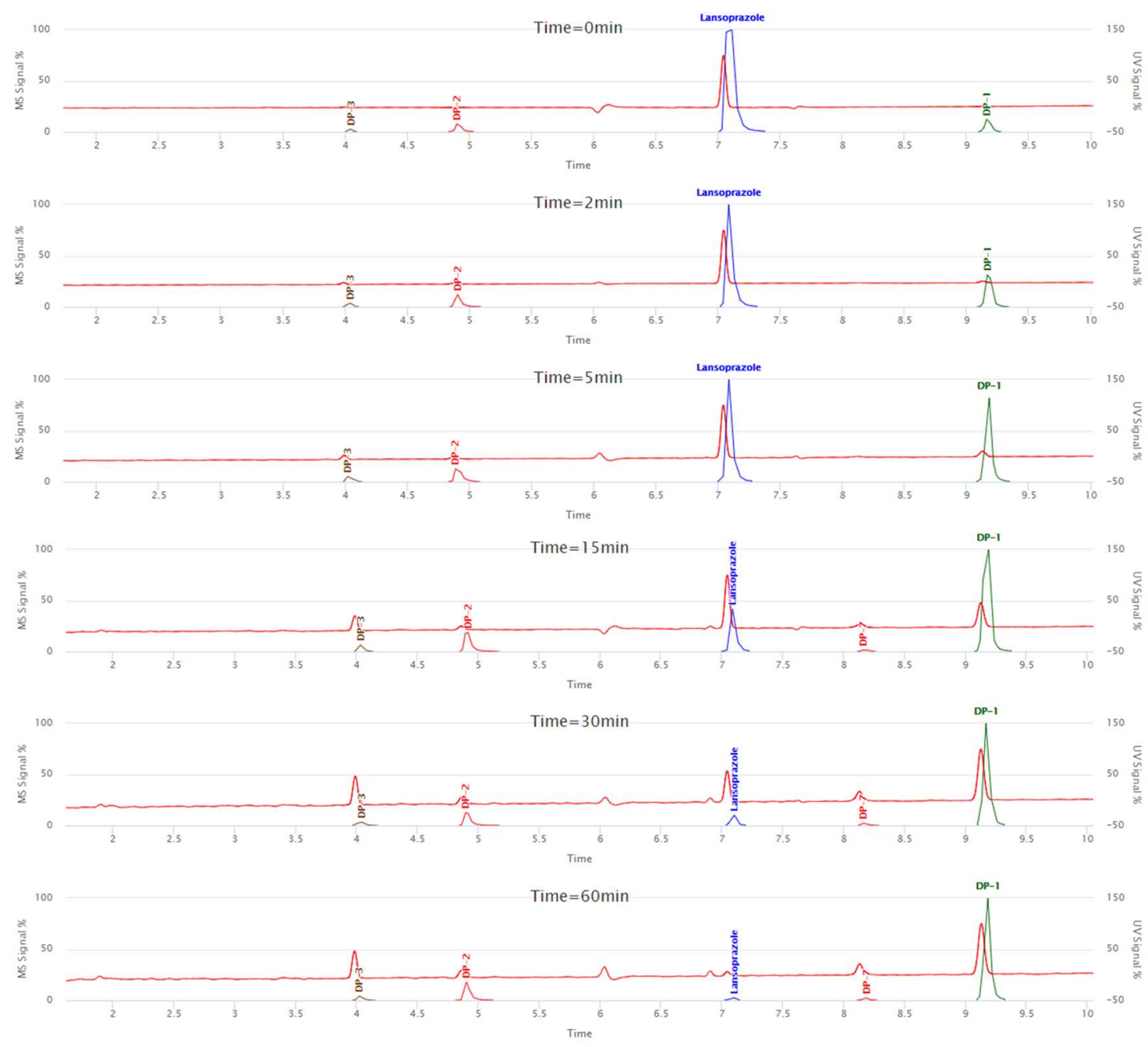

Figure S2. LC of all the datapoints for the experiment under acidic condition acquired in Agilent Q-TOF instrument. 

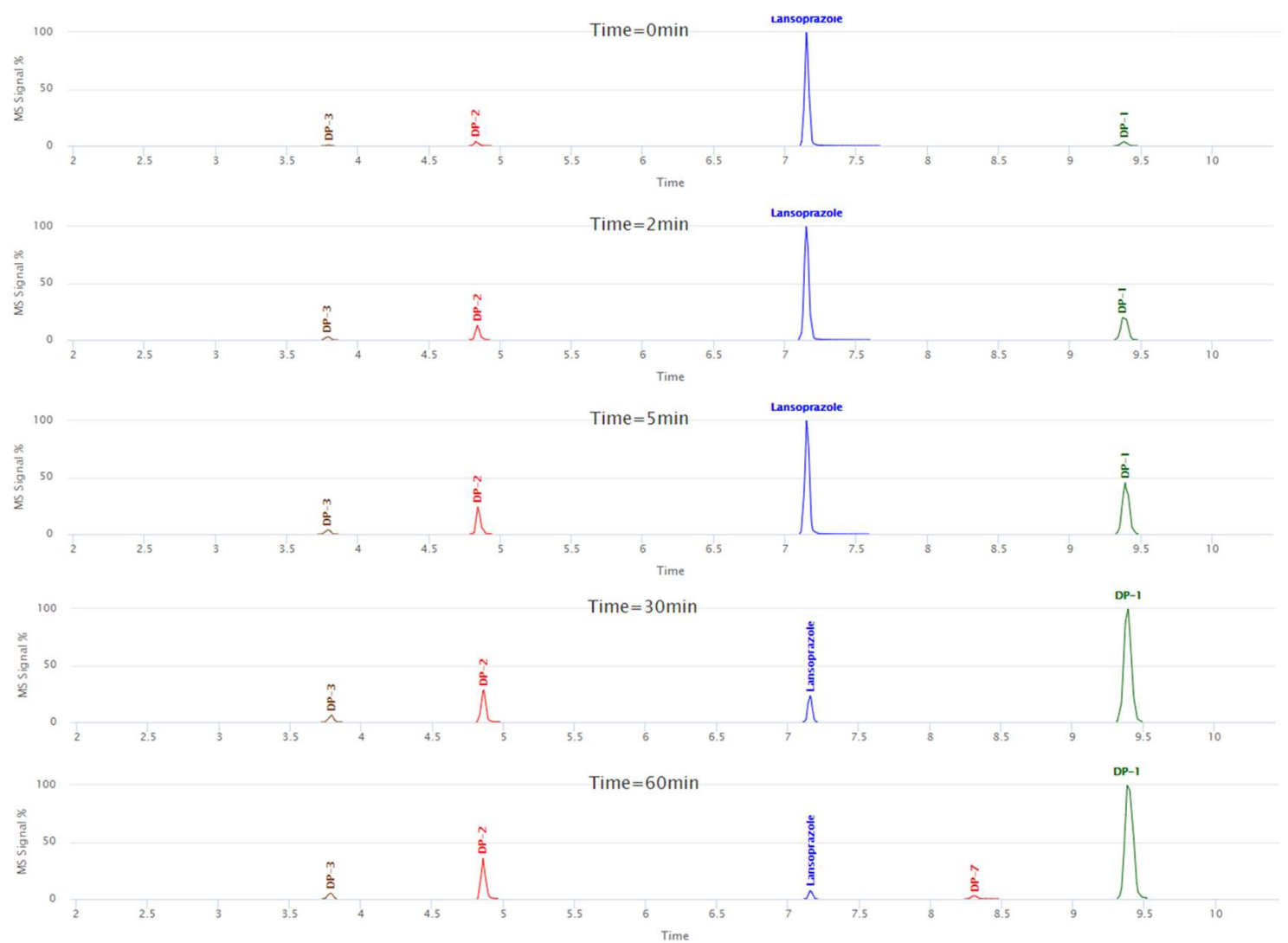

Figure S3. LC of all the datapoints for the experiment under acidic condition acquired in Thermo Q-Exactive instrument. 
a)

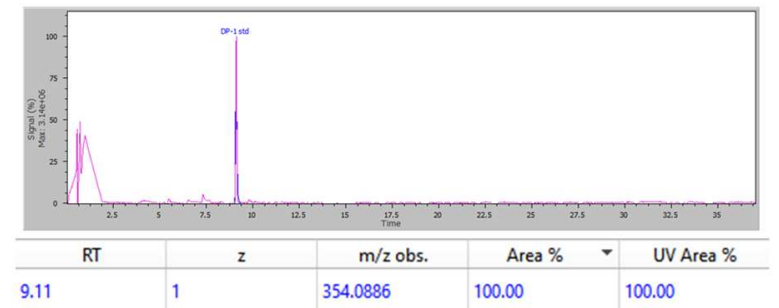

c)

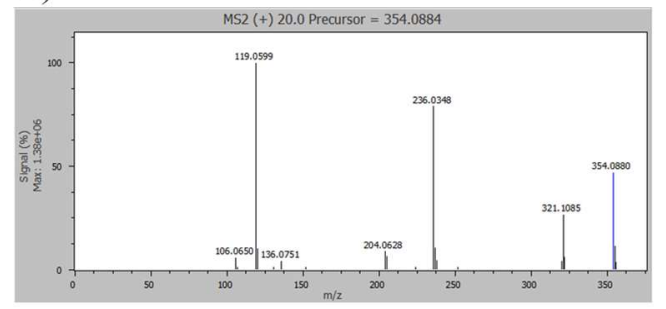

b)

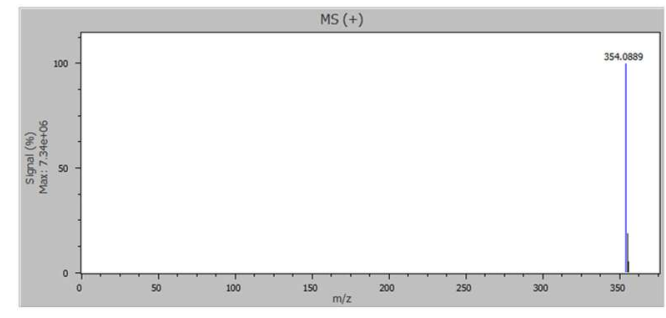

d)

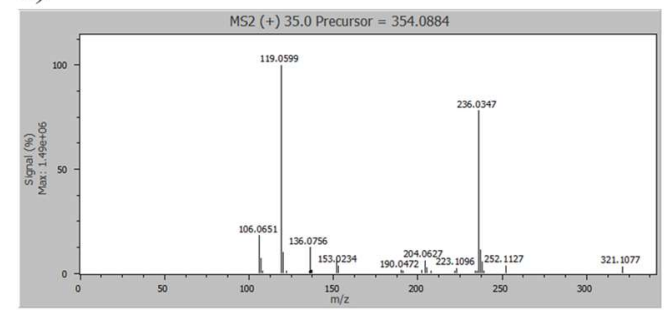

Figure S4, LC-MS/MS data from the DP-1 standard (Q-TOF instrument): LC and summary table (a), MS (b), $\mathrm{MS} / \mathrm{MS}$ at $20.0 \mathrm{~V}$ (c) and MS/MS $35.0 \mathrm{~V}$ (d) 
a)

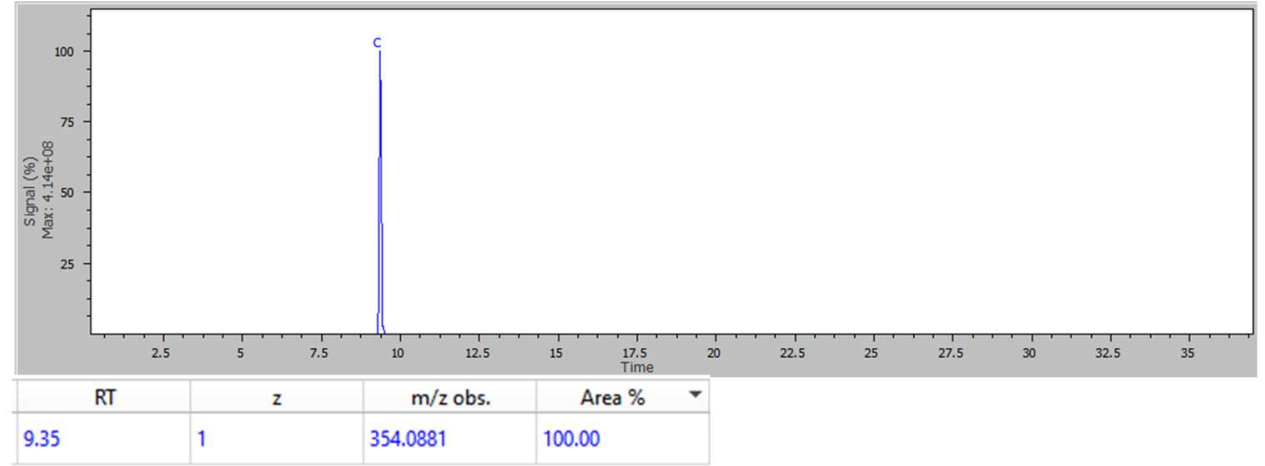

b)

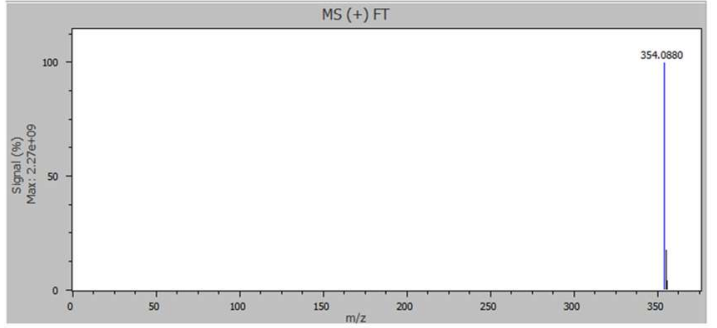

c)

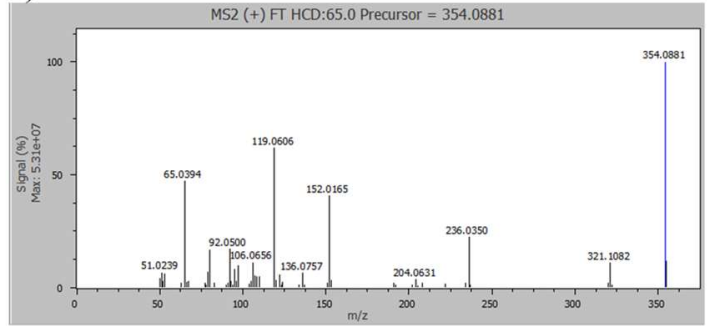

Figure S5. LC-MS/MS data from the DP-1 standard (Q-Exactive instrument): LC and summary table (a), MS (b) and $\mathrm{MS} / \mathrm{MS}$ at $65.0 \mathrm{~V}(\mathrm{c})$ 


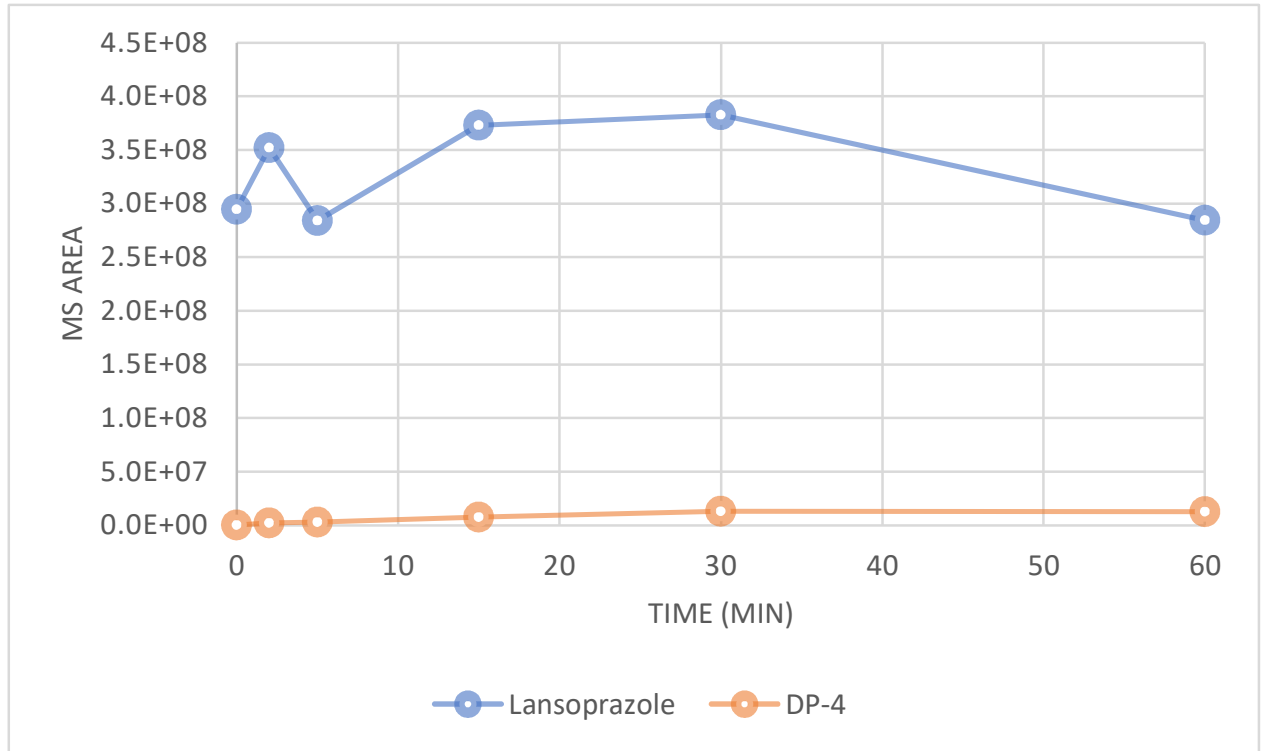

Figure S6. Time evolution of MS Area of lansoprazole and its found degradant under oxidative conditions. Data obtained with Thermo Q-Exactive instrument. 

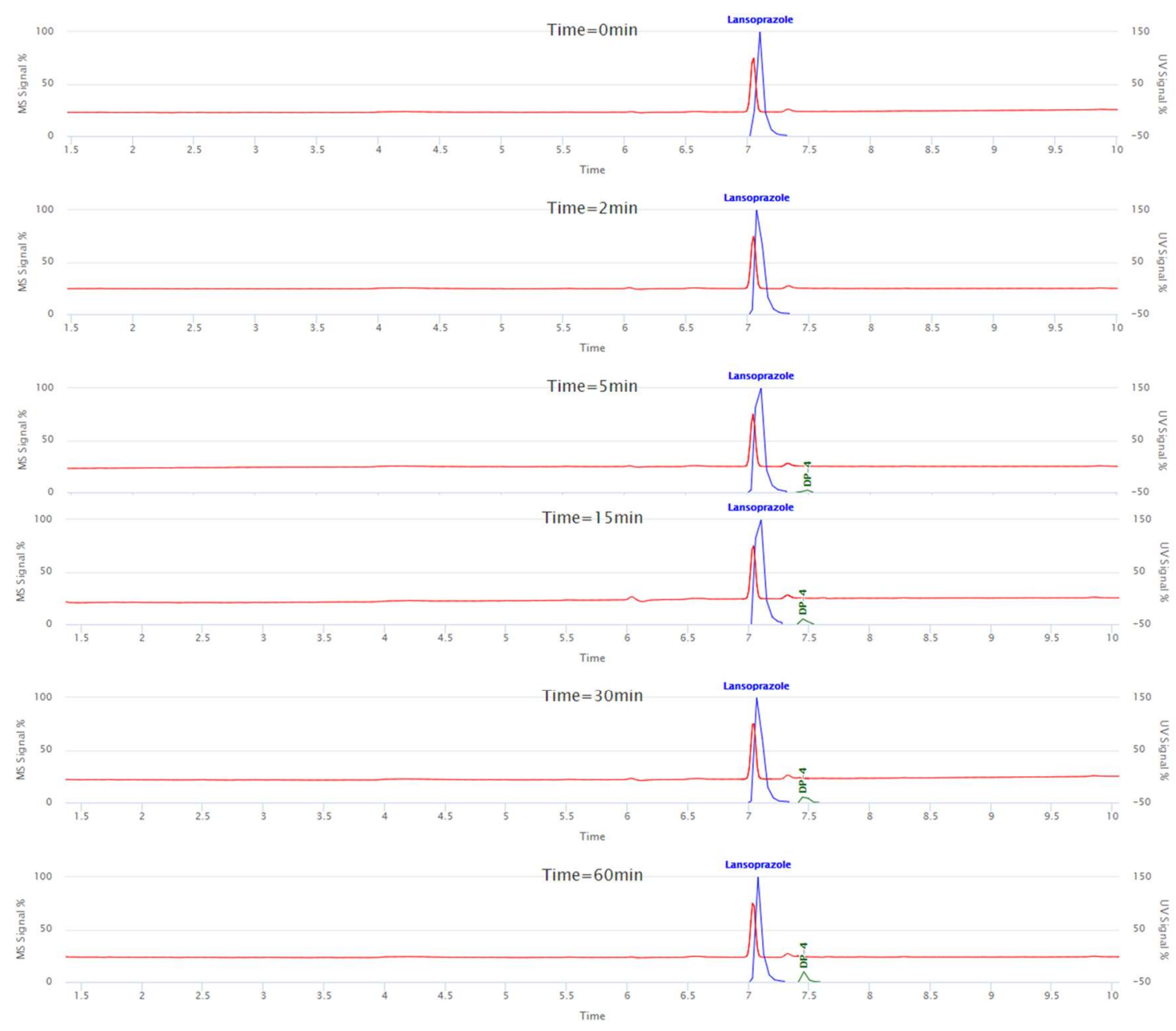

Figure S7. LC of all the datapoints for the experiment under oxidative stress condition acquired in Agilent Q-TOF instrument. 


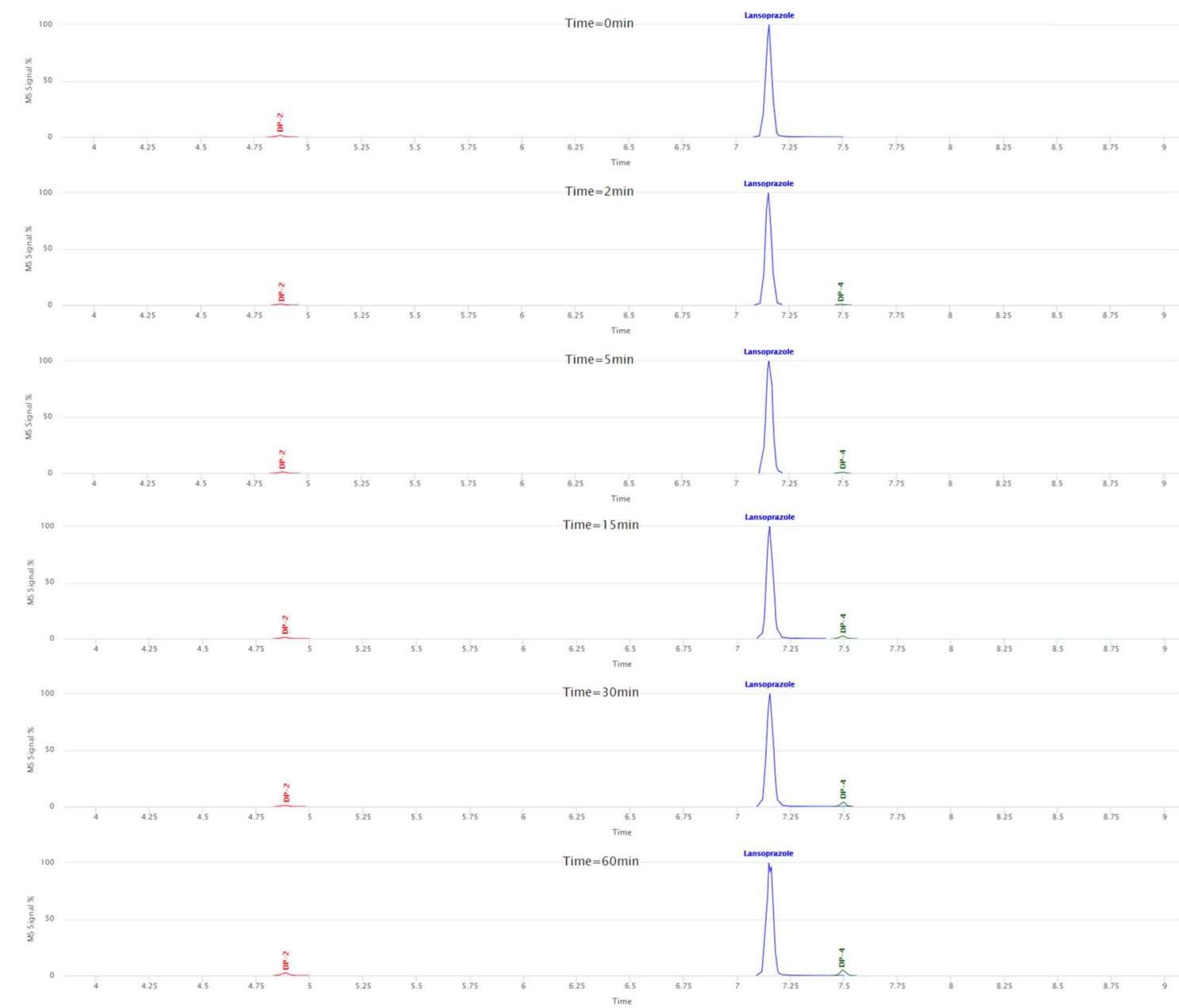

Figure S8. LC of all the datapoints for the experiment under oxidative stress condition acquired in Thermo QExactive instrument. 
a)

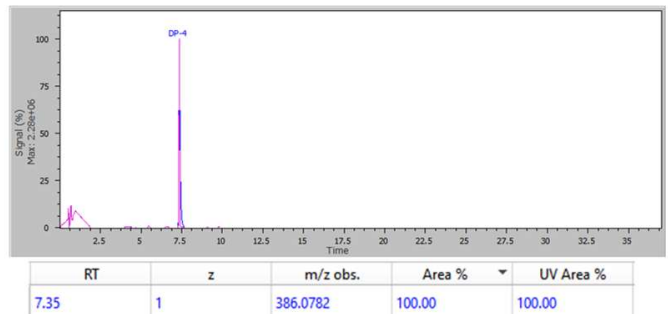

c)

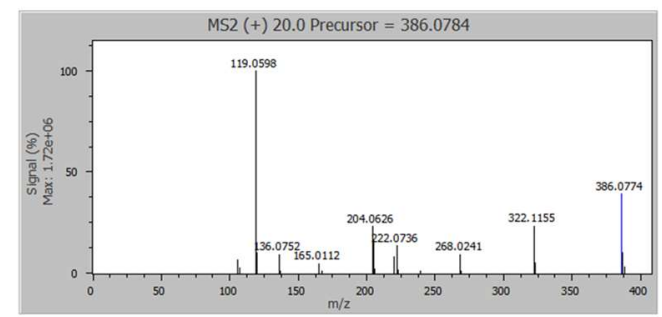

b)

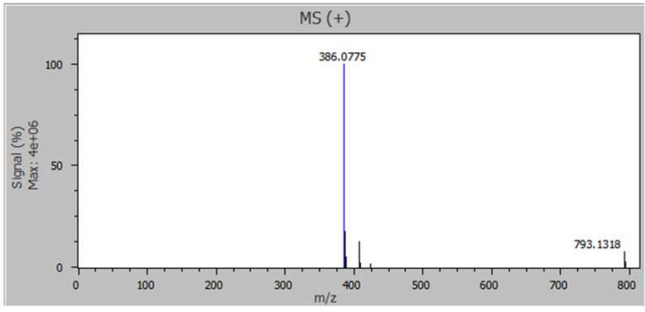

d)

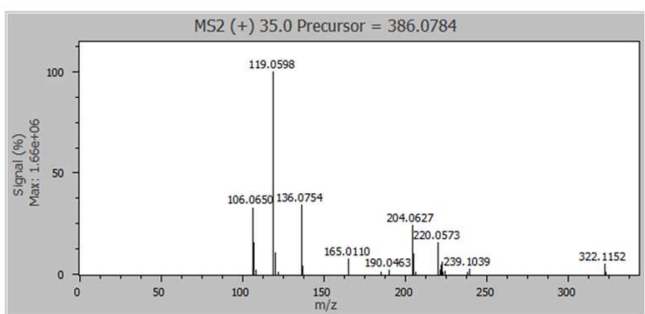

Figure S9. LC-MS/MS data from the DP-4 standard (Q-TOF instrument): LC and summary table (a), MS (b), $\mathrm{MS} / \mathrm{MS}$ at $20.0 \mathrm{~V}$ (c) and MS/MS 35.0 V (d). 
a)

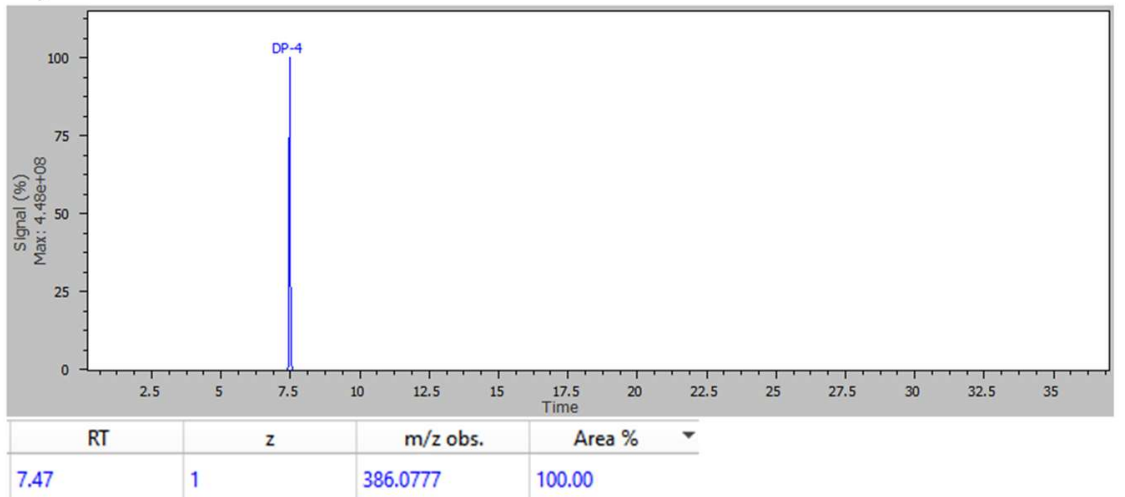

b)

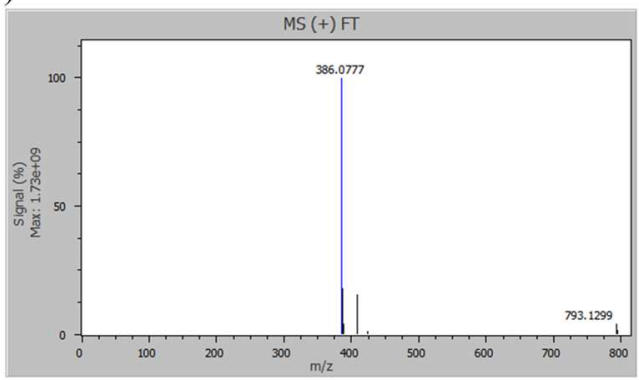

c)

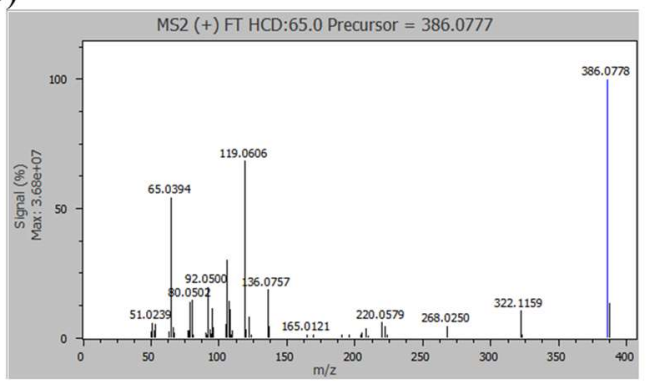

Figure S10. LC-MS/MS data from the DP-4 standard (Q-Exactive instrument): LC and summary table (a), MS (b), $\mathrm{MS} / \mathrm{MS}$ at $65.0 \mathrm{~V}$ (c). 


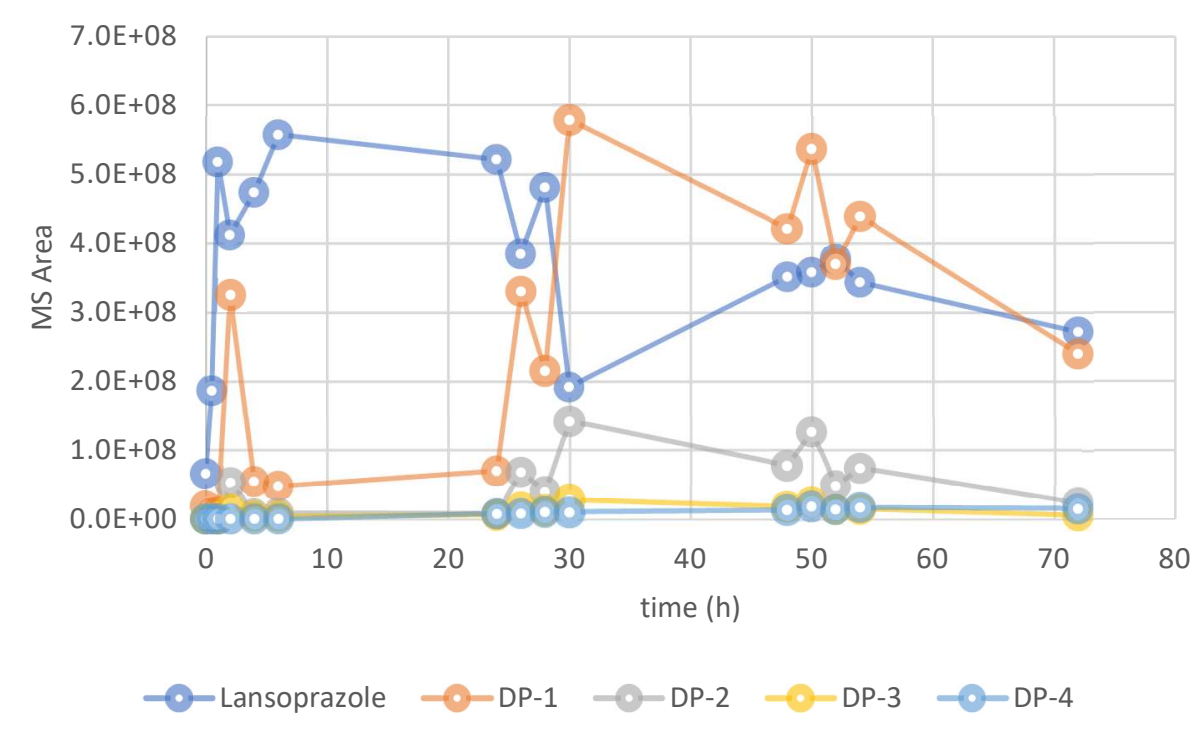

Figure S11. Time evolution of MS Area of lansoprazole and its found degradants under basic stress conditions. Data obtained with Thermo Q-Exactive instrument. 

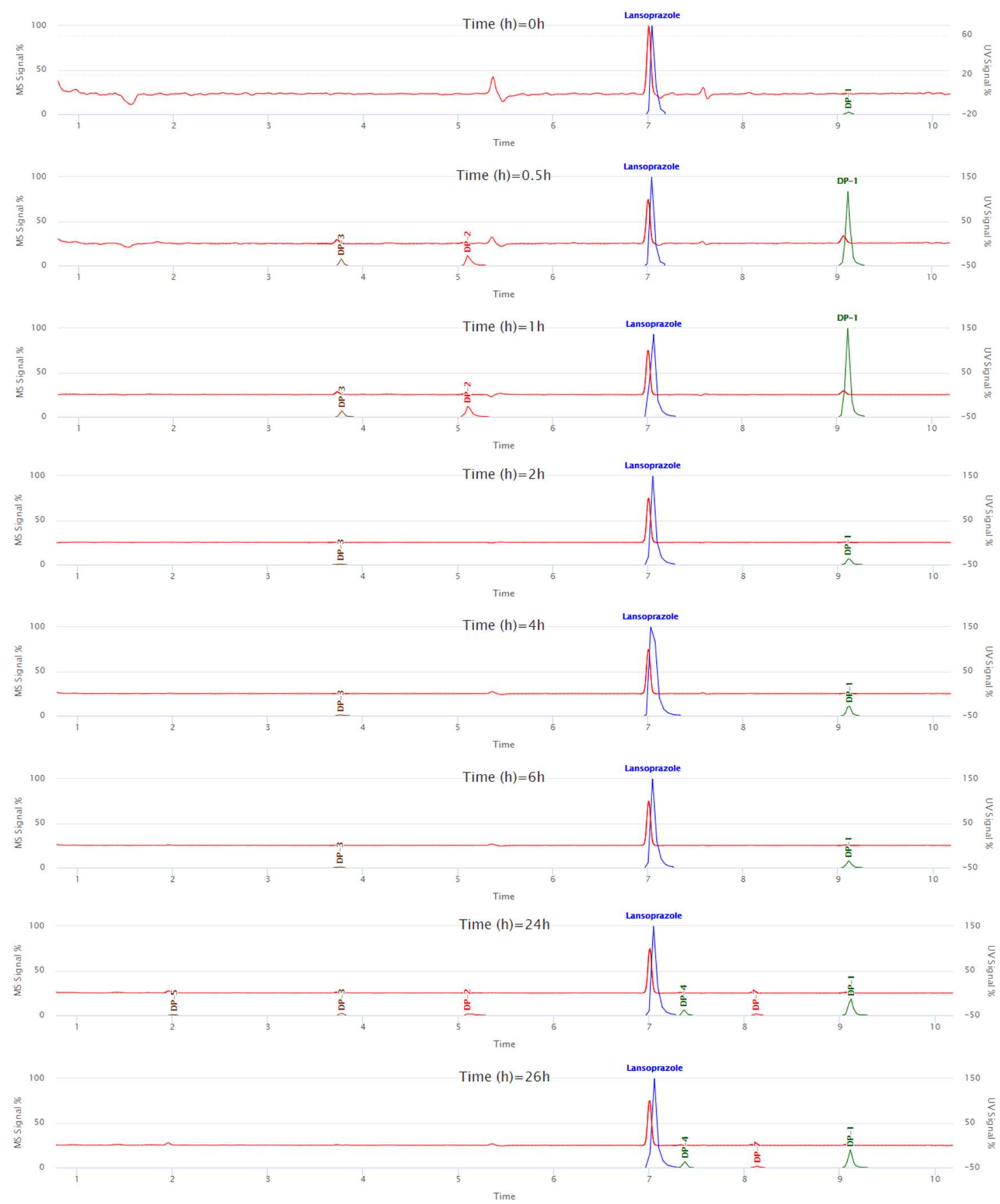

Figure S12a. LC of all the datapoints for the experiment under basic stress condition acquired in Agilent Q-TOF instrument. 

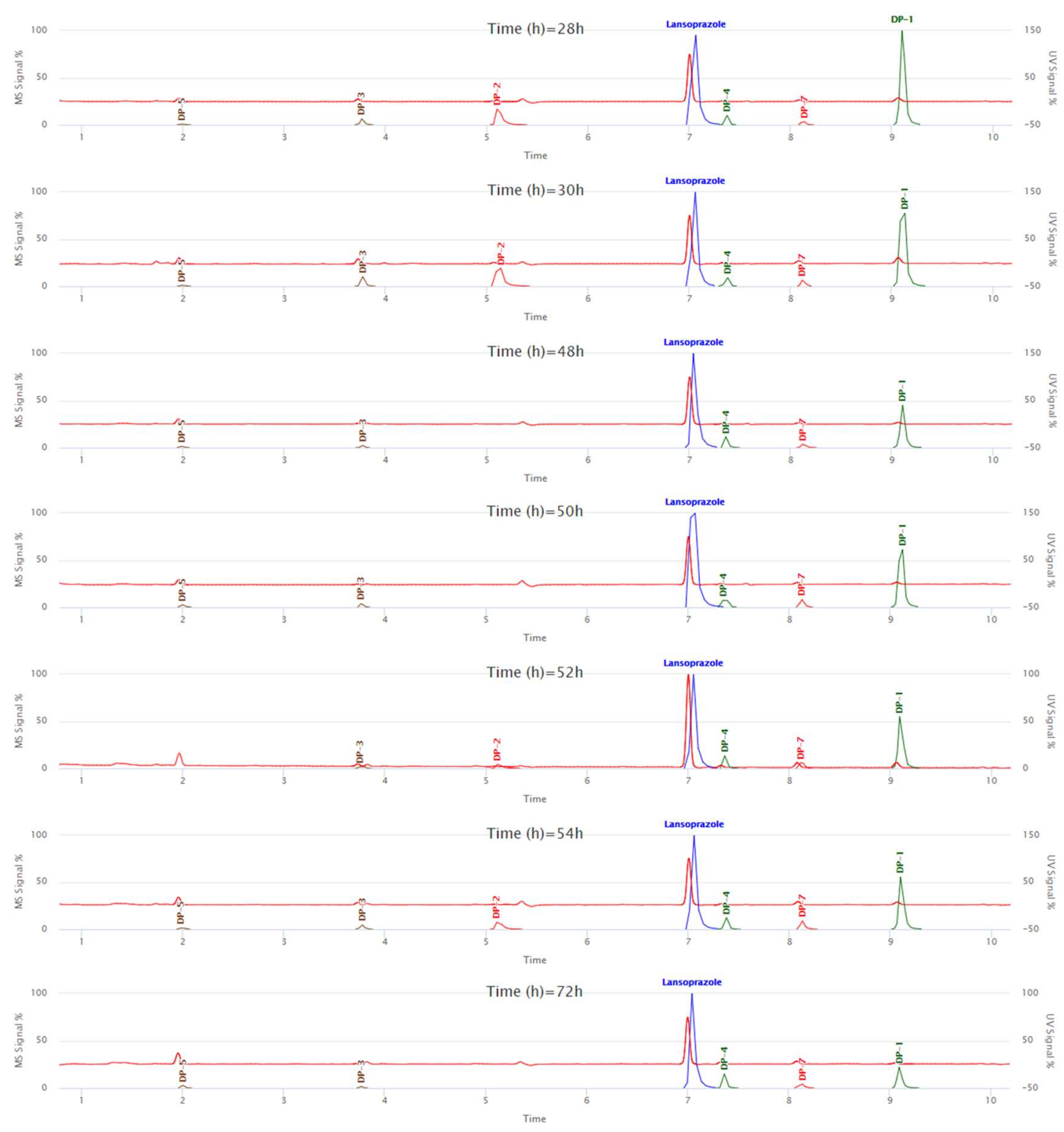

Figure S12b. LC of all the datapoints for the experiment under basic stress condition acquired in Agilent Q-TOF instrument. 


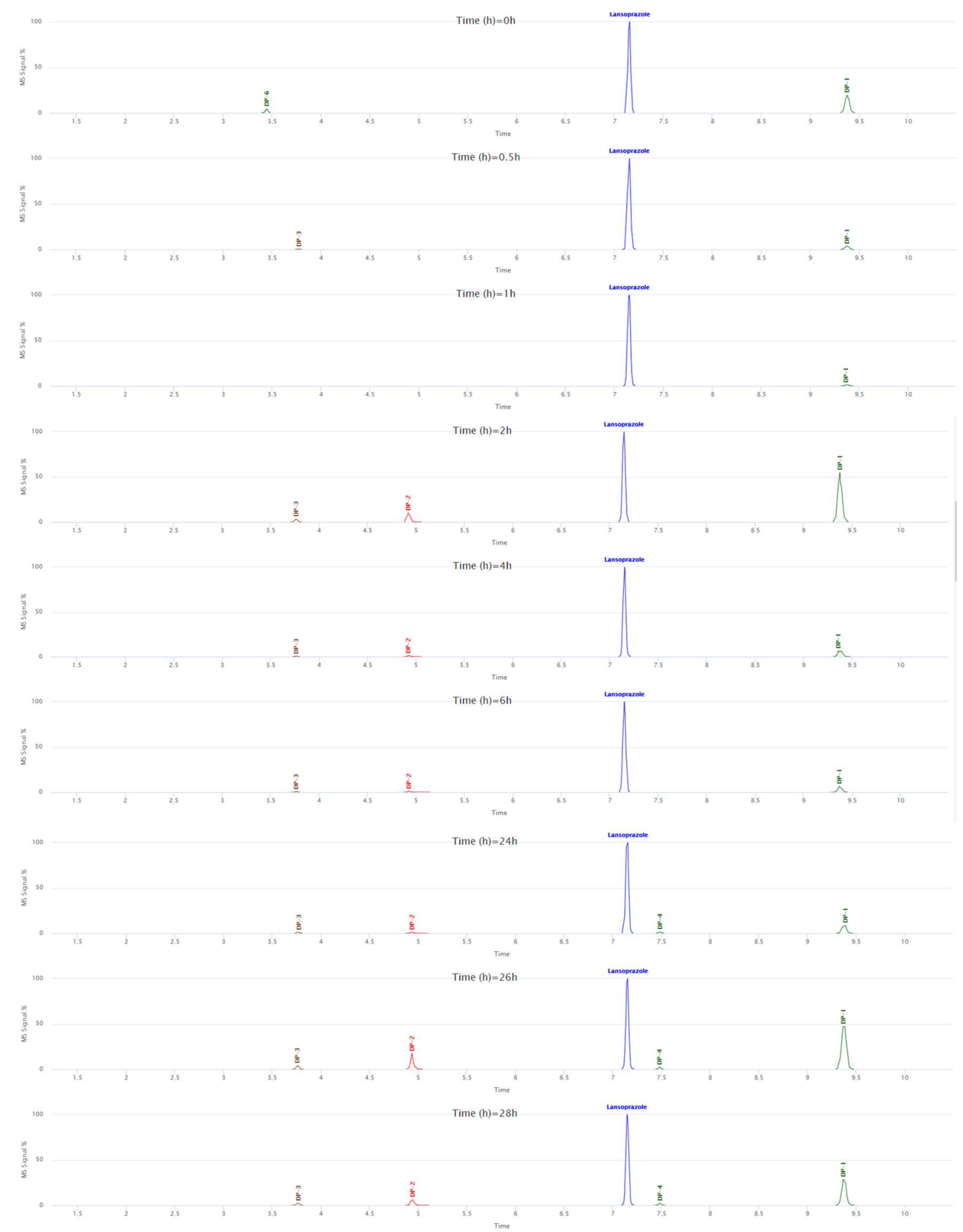

Figure S13a. LC of all the datapoints for the experiment under basic stress condition acquired in Thermo Q-Exactive instrument. 


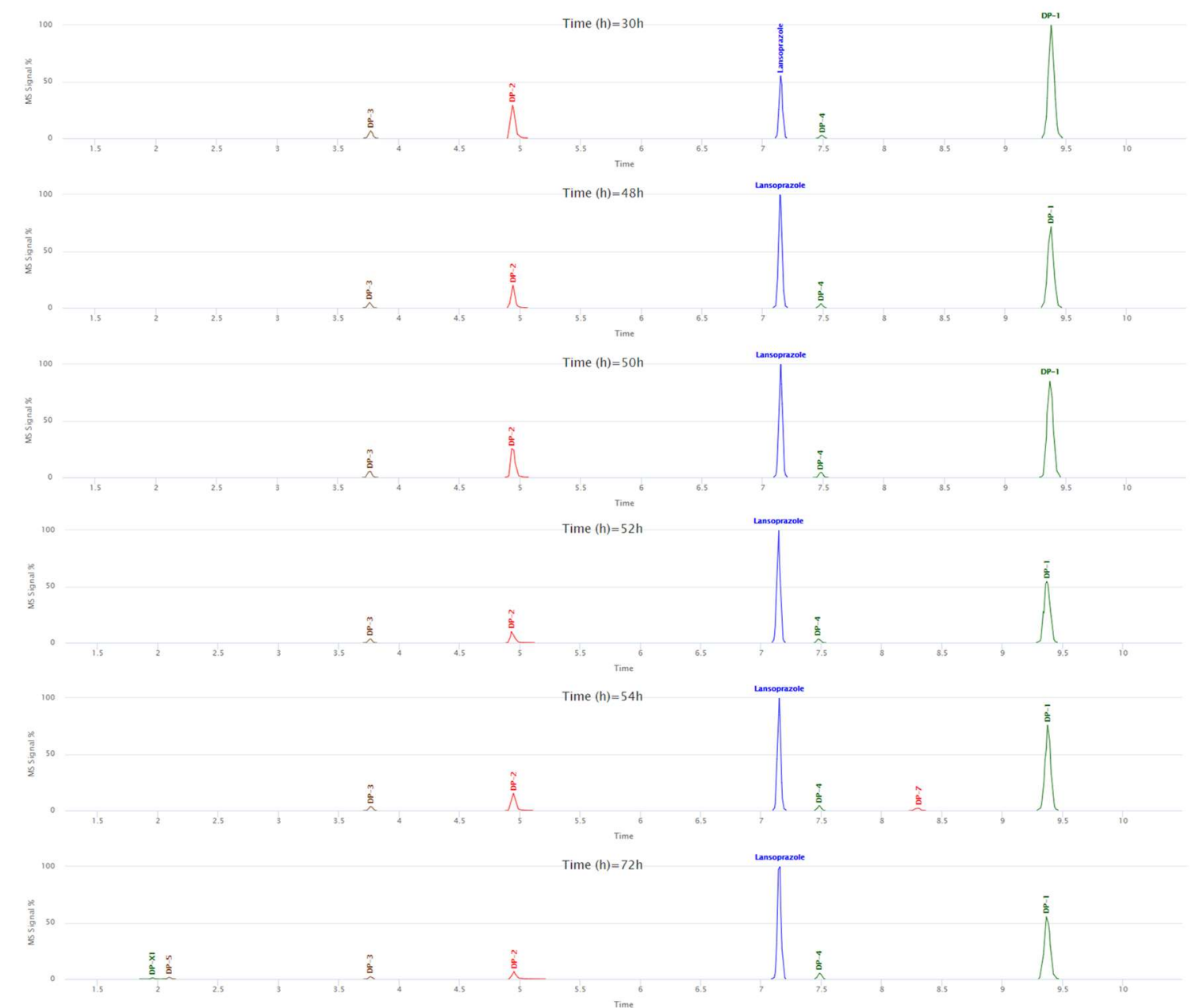

Figure S13b. LC of all the datapoints for the experiment under basic stress condition acquired in Thermo Q-Exactive instrument. 


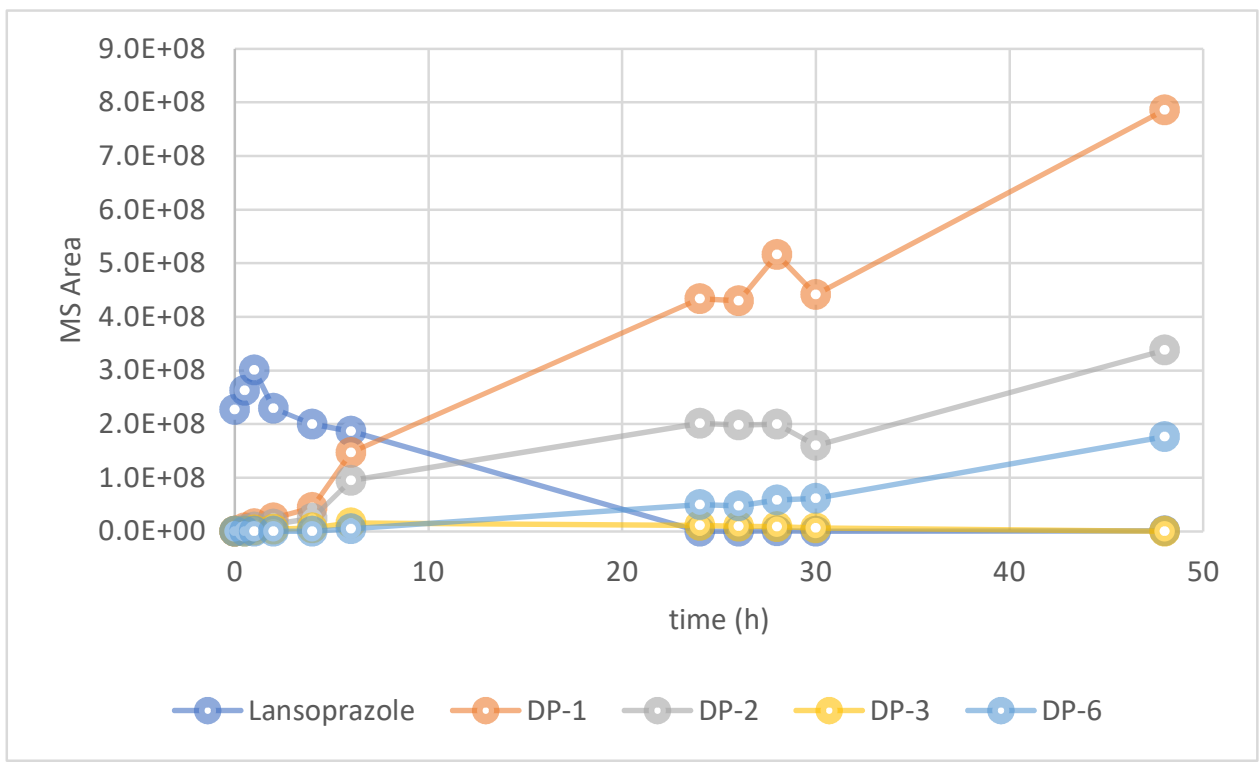

Figure S14. Time evolution of MS Area of lansoprazole and its found degradants under neutral stress conditions. Data obtained with Thermo Q-Exactive instrument. 

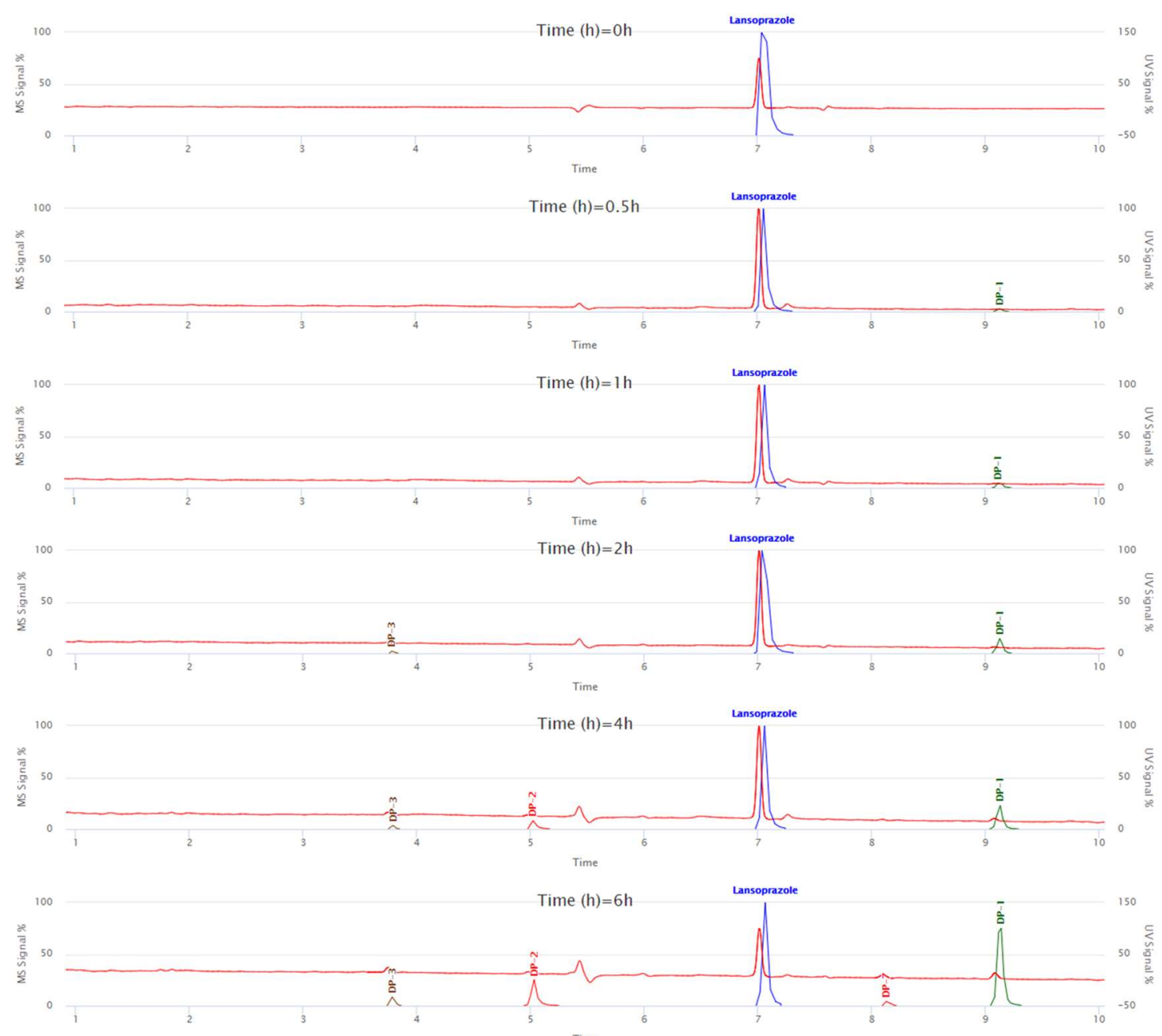

Figure S15a. LC of datapoints from $0 \mathrm{~h}$ to $6 \mathrm{~h}$ for the experiment under neutral stress condition acquired in Agilent QTOF instrument. 

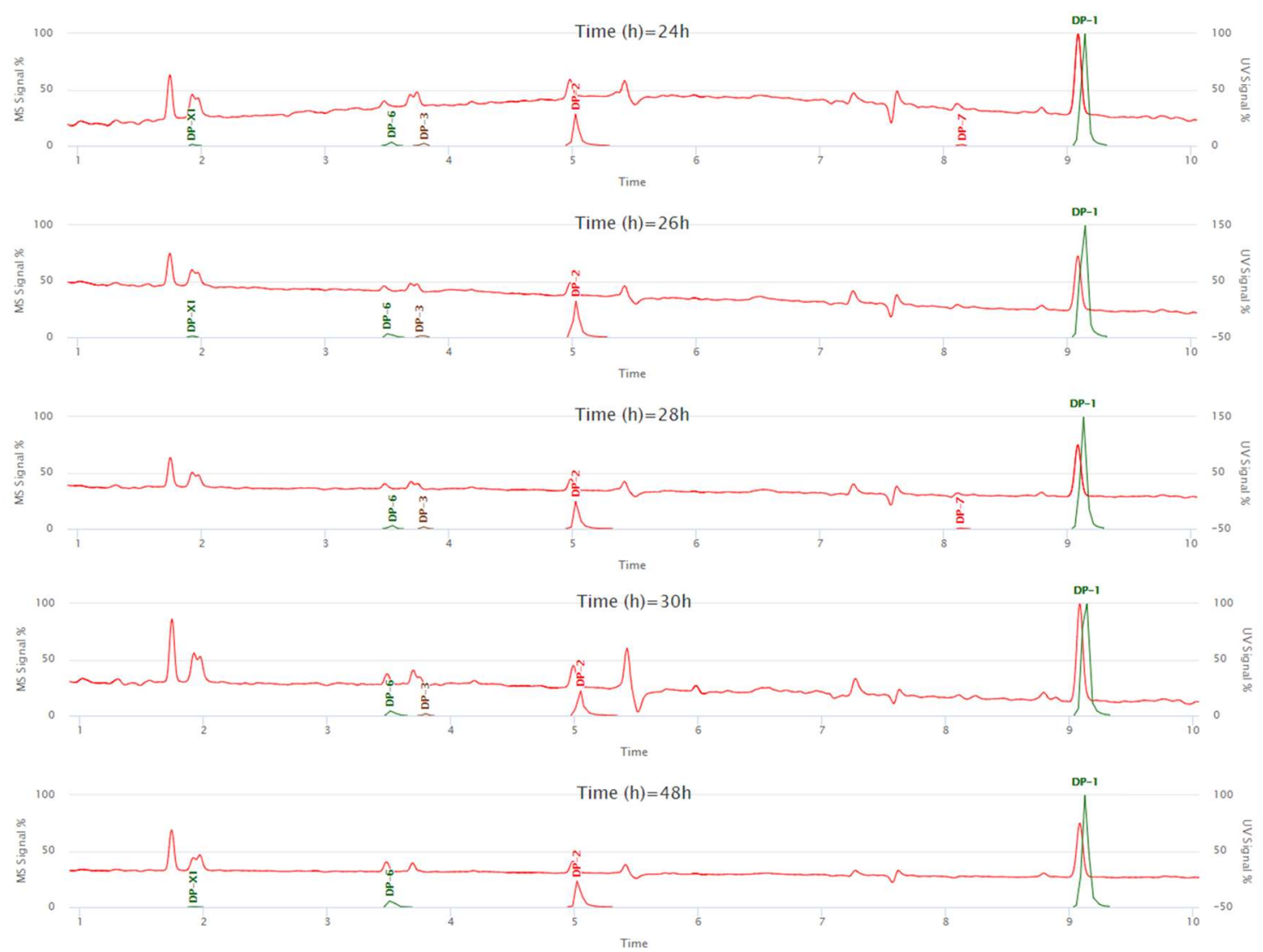

Figure S15b. LC of all the datapoints for the experiment under neutral stress condition acquired in Agilent Q-TOF instrument. 


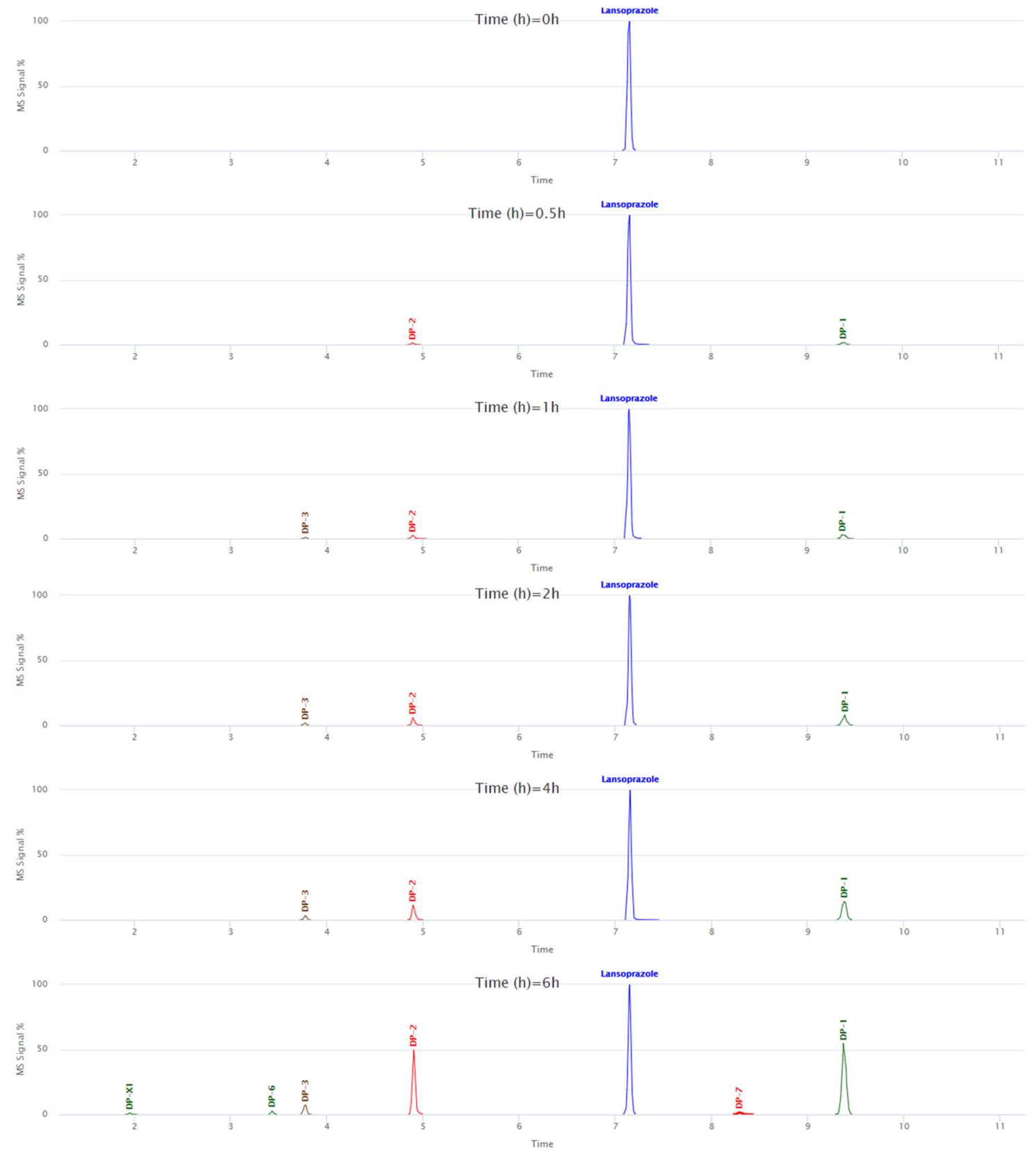

Figure S16a. LC of all the datapoints for the experiment under neutral stress condition acquired in Thermo QExactive instrument. 

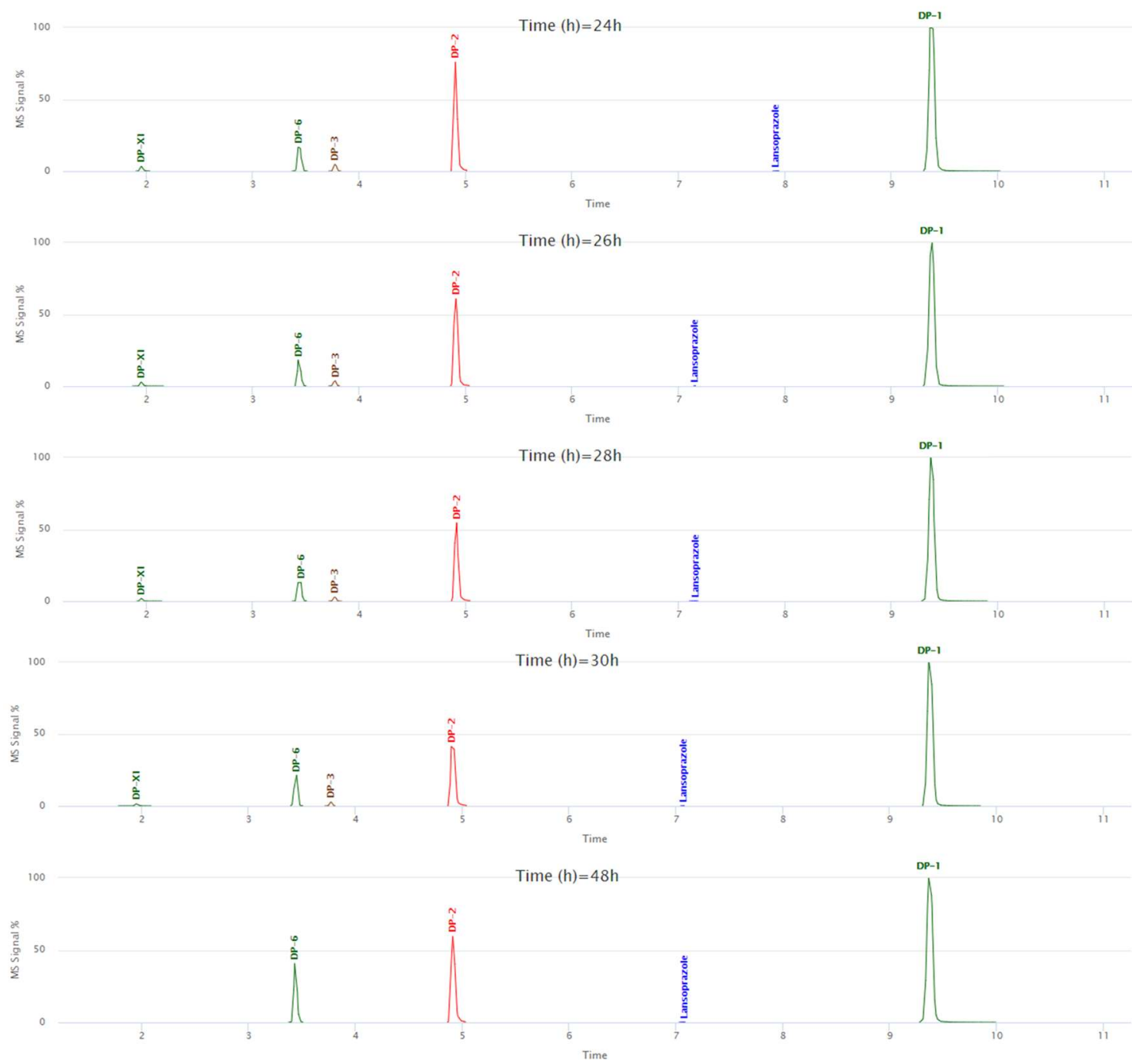

Figure S16b. LC of all the datapoints for the experiment under neutral stress condition acquired in Thermo QExactive instrument. 